\title{
АКАДЕМИЧЕСКАЯ КАРЬЕРА ПРОФЕССОРА АНДЕРСА АЛКВИСТА И ЕГО РОЛЬ В СОВРЕМЕННОЙ БРИТАНСКОЙ НАУКЕ
}

\section{ACADEMIC CAREER OF PROFESSOR ANDERS AHLQVIST AND HIS ROLE IN MODERN BRITISH SCIENCE}

\section{Ju. Gavrilova}

Summary: The article reveals basic stages of academic achievement of Anders Ahlqvist, British scientist of Finnish origin who dealt with Celtic studies. The author also introduces the definition of celtology and studies some works written by the scientist.

Keywords: career, Celtic studies, interdisciplinary character, congress, Celtic languages and culture.
$\Pi$ рофессор Андерс Алквист (Anders Ahlqvist, 19452018), об исследованиях которого пойдёт речь в статье, лингвист финского происхождения, родился в Швеции и вырос в Каире. Образование получил в Эдинбурге и Дублине. Его карьеру можно с уверенностью охарактеризовать как весьма успешную, связанную с работой не в одной стране и даже не на одном континенте, но неизменно при этом сконцентрированную на кельтских исследованиях (а именно, древнем ирландском и валлийском языках), т.к. стремился к позиционированию кельтских исследований как глобальной научной дисциплины.

Как указано в лингвистическом энциклопедическом словаре, «кельтология - это комплекс гуманитарных дисциплин, изучающих языки, литературу, историю, этнографию и археологию кельтских народов. Лингвистическая кельтология занимается изучением кельтских языков. Представление о генетическом единстве кельтских языков восходит к началу XVII века. ... Основателем кельтологии как науки является И.К. Цейс (Zeuss, на латинском языке), который опубликовал в 1853 году сравнительноисторический труд Grammatica Celtica» [13], где впервые были установлены строго закономерные фонетические соответствия между кельтскими и другими индоевропейскими языками» [3].

Журнал «Наука и жизнь» так пишет о кельтах: «Кельты - загадочный народ, потомки которого и сейчас живут в Европе. Близкие по языку и культуре племена, известные в истории под именем кельтов (это название идет от древних греков, римляне их называли галлами), примерно три тысячи лет назад расселились почти по всей Европе. Их пребывание на континенте отмечено многими успехами в области материальной культуры,
Гаврилова Юлия Викторовна

К.филол.н., дочент, Московский гуманитарный университет, March1378@yandex.ru

Аннотация: В статье отражены основные этапы академических достижений профессора Андерса Алквиста, британского исследователя-кельтолога финского происхождения. Автор также знакомит читателя с понятием кельтология, рассматривает некоторые работы учёного.

Ключевые слова: карьера, кельтские исследования, междисциплинарный характер, конгресс, кельтские языки и культура.

которыми пользовались и их соседи. Ранняя европейская литература, вернее фольклор, немало почерпнула из памятников творчества этого древнего народа. Герои многих средневековых сказаний - Тристан и Изольда, принц Айзенхерц (Железное сердце) и волшебник Мерлин - все они были рождены фантазией кельтов. В их героических сагах, записанных в VIII столетии ирландскими монахами, фигурируют сказочные рыцари Грааля, такие, как Персифаль и Ланселот. Сегодня довольно мало пишется о жизни кельтов и той роли, которую сыграли они в истории Европы. Больше повезло им в современной развлекательной литературе, главным образом во французских комиксах. Кельтов рисуют, как и викингов, эдакими варварами в рогатых шлемах, любителями выпить и полакомиться кабанятиной»[1].

Именно в свете сохраняющейся до наших дней недостаточной изученности кельтской тематики, а также произведений Алквиста, исследования профессора, на наш взгляд, и представляют собой особую ценность для научного сообщества филологов нашей страны.

Нельзя не сказать несколько слов об академической карьере учёного. Алквист получил докторскую степень в 1974 году в Эдинбургском университете, защитив работу под названием «История наречий в ирландском языке» (The History of the Adverb in Irish). Затем он провел 2 года в Школе Кельтских исследований (School of Celtic Studies) [4] в Дублинском университете, а в 1976 году начал преподавать древний и средний ирландский язык (Old and Middle Irish) в Национальном университете Ирландии, городе Галвэй (Galway), где стал профессором и в 2005 году стал руководить кафедрой древнего и среднего ирландского языка и кельтской филологии (Chair of Old and Middle Irish and Celtic Philology) [10]. 
Проработав в этом университете на протяжении 30 лет, совмещая эту должность с лекциями в других странах и городах, Алквист впоследствии переехал в Австралию и возглавил кафедру кельтских исследований (Chair of Celtic Studies) в Сиднейском университете в 2009 году, на которой и трудился вплоть до выхода на пенсию в 2013 году.

Однако, обладая широким кругозором, большой эрудицией и академическим складом ума, профессор Алквист не только занимался научными исследованиями в своей области, но и многие годы посвятил руководству Обществом истории изучения лингвистических идей имени Генри Суита (The Henry Sweet Society for the History of Linguistic Ideas), руководству Школой кельтских исследований Дублинского университета (DIAS, Dublin Institute for Advanced Studies) [4]. Кроме того, исследователь выступал в качестве вице-президента Общества истории и эпистемиологии лингвистики (1984-1992), президента Европейского лингвистического общества (2002-2003), секретаря Международного конгресса кельтских исследований (2003-2018). В целом же можно говорить о том или ином участии профессора в работе порядка 100 научных организаций и научных обществ мира.

Помимо членства в научных ассоциациях и объединениях, Андерс Алквист активно участвовал в организации и проведении научных мероприятий, среди наиболее значимых можем отметить VI-й Международный конгресс по кельтским исследованиям (The Sixth International Congress of Celtic Studies) $и$ V-ю Международную конференцию по исторической лингвистике (The Fifth International Conference on Historical Linguistics). Оба указанные мероприятия состоялись в Галвэе в 1979 и 1981 годах соответственно. Помимо работы в оргкомитетах он принял участие в подготовке к изданию сборников материалов конференций. Важно подчеркнуть также, что Алквист проявлял особый интерес к проблематике истории лингвистических идей в целом.

Если поставить себе цель выразить объём изданных профессором работ в количественных показателях, то можно насчитать порядка 130 работ [11], ценных прежде всего своим междисциплинарным характером. Как уже было сказано выше, большая часть исследований касалась лингвистических аспектов кельтских языков. Но благодаря владению шведским, английским, финским, французским, ирландским и немецким языками Андерс Алквист одновременно является автором статей на этих и об этих языках, что, конечно, демонстрирует феноменальную эрудицию и несомненный лингвистический исследовательский талант. Более того, статьи касались не только современных аспектов языков, но также их классических, современных, средневековых вариантов и проблем.
Так, весьма существенным вкладом Алквиста в исследование проблематики истории лингвистических учений стала его монография, опубликованная под заголовком «Ранне-ирландский лингвист» (The Early Irish Linguist) [11] Финским обществом науки и филологии (The Finnish Society of Sciences and Letters) в 1983 году. Она была посвящена на тот момент незаслуженно забытому средневековому тексту по грамматике ирландского языка. И хотя монография содержала всего 81 страницу, она кардинальным образом изменила понимание роли средневековых ирландских учёных и их вклада в историю лингвистических идей в общеевропейском контексте.

Значимость научной деятельности профессора Алквиста и уважение, которым он неизменно пользовался среди коллег, демонстрируют изданные в его память два сборника статей. Первый из них вышел в свет в 2005 году под названием "Companion in Linguistics”, был приурочен к 60- летию профессора и включал 27 статей, написанных в основном членами Общества Генри Суита и посвящённых кельтской фонологии и лингвистике, лингвистической историографии и общему языкознанию.

Второй сборник был опубликован усилиями его коллеги по работе в Австралии, Памелой О'Нейл, в связи с выходом профессора на пенсию «Сиднейская серия кельтских исследований» (Sydney Series in Celtic Studies).

Андерс Алквист также оказал огромное влияние на изучение кельтской проблематики в Австралии. Кроме того, научное сообщество как Великобритании, так и Австралии единодушно отмечает то позитивное влияние, которое профессор оказывал на молодых ученых, вдохновляя их на проведение исследований, что, на наш взгляд, служит важным обстоятельством для движения любой науки вперед.

Так как рамки настоящей статьи не позволяют нам осветить в полной мере содержание разнообразных публикаций исследователя, остановимся более подробно лишь на одной из его работ [6]. Audacht Morainn - в переводе «Свидетельство Моранн» - это древнеирландский текст, который посвящён королевской власти, вопросам организации и благосостояния общества. Свидетельства Моранн - это последние наставления пожилого судьи Моранн молодому королю, в которых судья даёт рекомендации по правильному руководству, а центральная идея их заключается в том, что процветание людей зависит от справедливости руководителя.

В работе отмечается, что текстуальная история «Свидетельства Моранн» весьма сложна, так как первоначальное издание «Свидетельства» выдержало несколько трактовок и переводов, при которых происходила неоднократная трансформация первоначального текста. Алквист сопоставляет существующие переводы текста 
на разные языки и трактовки лексических и грамматических явлений, встречающихся в тексте, осуществляет перевод текста на французский язык.

Так, например, если древнеирландский глагол "clandas" употреблен в тексте послания в финальной позиции предложения, то согласно стандартной лингвистической теории, он приобретает коньюнктивное окончание (conjunctive ending). Перевод на английский язык отрывка текста (наблюдаем в тексте упомянутый выше глагол), написанного на древнеирландском "Is tre fir flathemon cech comarbe cona chli ina chairnobu clandas", может быть примерно таким: "It is through Prince's truth - every heir settles with his house-post in his fair inheritance" [6, p.4].

Сложности при реконструкции оригинального древнеирландского текста, по мнению лингвиста, связаны в основном с тем, что с каждым новым его переизданием что-то новое привносилось редакторами, а что-то, наоборот, не было включено. Исследование профессора Алквиста выявило тот круг проблем, с которыми неизбежно сталкиваются специалисты по языкознанию и исторической лингвистике. «С одной стороны, слишком большая опора на лингвистическую теорию зачастую приводит к созданию языковых форм, существование которых в древних текстах ничем не подкреплено, и, с другой стороны, при одновременном использовании многих рукописных источников, ученым вполне удается воссоздать тексты, имеющие лингвистическую и филологическую ценность» $[6$, р.8].
Далее упомянем названия некоторых важных работ исследователя: "Some Aspects of the Copula in Irish" [7], "Celts and Their Culture at Home and Abroad" [8]. Полный список можно найти в библиографии его работ [11].

Как уже отмечалось выше, профессор Алквист был не только автором научных работ, но и зачастую также редактором научных сборников. Например, под его редакцией вышли такие сборники по материалам научных конференций, как "Papers from the Fifth International Conference on Historical Linguistics, Galway, April 6-10, 1981" [12], " Diversions of Galway: Papers on the History of Linguistics" [9]и многие другие.

Подводя итог, следует отметить, что работы Андерса Алквиста, без сомнения, вносят существенный вклад в сферу современной лингвистической кельтологии, заполняют имеющиеся в ней пробелы и предлагают новое прочтение текстов древних источников. Поэтому проблематика трудов профессора может представлять интерес как для лингвистов-филологов, так и, конечно, для специалистов - кельтологов в широком смысле. Сами работы Алквиста могут вполне послужить основой научных исследований филологов, занимающихся вопросами британского языкознания, историей лингвистических учений и культурой, и письменными памятниками кельтских племён. Полная библиография работ была подготовлена Д. Хайден совместно с К. Квирк в 2020 году [11].

\section{ЛИТЕРАТУРА}

1. Александровский Г. Кельты - загадочный народ, потомки которого и сейчас живут в Европе // Наука и жизнь, №3, 1998. [электронный ресурс] URL: https://www.nkj.ru/archive/articles/10396/

2. Калыгин В.П., Королев А.А. Введение в кельтскую филологию. М.: Комкнига, 2006. - 272 c.

3. Королёв А.А. Кельтология // Лингвистический энциклопедический словарь [электронный ресурс] URL: https://les.academic.ru/485/

4. Сайт Дублинского университета [электронный ресурc] URL: https://www.dias.ie/celt/

5. Ahlqvist A., P. O'Neill. Celts and Their Culture at Home and Abroad. A Festshrift for Malcolm Broun (Sydney Series in Celtic Studies 15). Sydney: The University of Sydney for the Celtic Studies Foundation, 2013. - $380 \mathrm{p}$.

6. Ahlqvist A. Paragraph 16 of Audacht Morainn: linguistic theory and philological evidence // Historical linguistics and philology, ed. by Jecek Fisiak. Berlin, New York: Mouton de Gruyter, 1990. pp.1-11.

7. Ahlqvist A. Some Aspects of the Copula in Irish // Eigse. A Journal of Irish Studies, №14/4. Dublin, National University of Ireland: Geimhreadh, 1972. - pp. 269-274.

8. Ahlqvist A., P. O'Neill. Celts and Their Culture at Home and Abroad. A Festshrift for Malcolm Broun (Sydney Series in Celtic Studies 15). Sydney: The University of Sydney for the Celtic Studies Foundation, 2013. - $380 \mathrm{p}$.

9. Diversions of Galway: Papers on the History of Linguistics from ICHoLSV, Galway, Ireland, 1-6 September 1990 // ed. by A. Ahlqvist, K. Koerner, R.H. Robins, I. Rosier. Philadelphia: John Benjamins Company, 1992. - 384 p.

10. Hayden D. In Memoriam. Anders Ahlqvist // Language and History, vol.63, iss.1, 2020. - pp. 91-95.

11. Hayden D., Quirke C. A Bibliography of the Publications of Anders Ahlqvist // Language and History, vol.63, iss.1, 2020. - pp. 96-103.

12. Papers from the Fifth International Conference on Historical Linguistics, Galway, April 6-10, 1981 // ed. by A. Ahlqvist. Amsterdam: John Benjamins Company, 1983. - 527 p.

13. Zeuss J.K. Grammatica Celtica. Paris: Maisonneuve \&amp., 1871. - 1115 р. [электронный ресурc] URL: https://archive.org/details/grammaticacelti03zeusgoog/ page/n1184/mode/2up 